\title{
The Effect of Pre-school Education on Language Comprehension of Children at Primary Level
}

\author{
Shaista Majid* \\ Shahid Hassan ${ }^{* *}$
}

\begin{abstract}
The research was designed to study the effect of pre-school on language comprehension of children at primary level. Preschool education is the education of young children, they got from the age of three years in proper school environment before class I. The research question was, whether preschool education has any contribution in understanding of English language of children, and in future academic progress of children at primary level. The comprehension of language was judged through tests based on English text for classes I to V. The sample of the study comprising 240 students, half preschoolers and half non preschoolers was randomly selected from four schools at Islamabad to whom tests were distributed to be done in a time limit. A statistical application of $\mathrm{t}$ test showed a significant difference in the performance of students having preschool education and the students without preschool education. It was concluded that the children who start their schooling at the age of three or more than three years acquired better English language writing skills than those who do not get educational experience in early years of their lives before entering in class I. It was recommended that arrangements may be made for preschool education of the children in our country.
\end{abstract}

Keywords: Preschool education, English language, comprehension, early years.

\footnotetext{
* Assistant Professor, Special Education, Allama Iqbal Open University, Islamabad

** Deputy Director, Federal Investigation Agency, Lahore
} 


\section{Introduction}

Preschool education is the education of young children, beginning in infancy and ending upon entry into primary school at the age six or seven years. This education is different from the day care centers in providing organized physical, emotional or intellectual development of children while the former provide services of only custodial care, safety and health services for the children of working mothers or for those children who can't be cared for at home (Encyclopedia Britannica, Vol. III). Fredrick Froebel says that early childhood development is a special phase because during this period a child expresses himself through play. From intellectual development point of view this age relates to second stage, i.e., representative intelligence (from 2 years to seven years). Piaget recognized for the first time the importance of cognitive learning process and concept formation in the young child. At this stage the child experiences the greatest language growth, words and with other symbols he expresses the symmetry. As stated in National Education Goals Panel (1991, p.21) the language development is an area which is addressed in seven benchmarks of a high quality preschool program that calls for the development of preschool children.

The main purpose of pre-school education is language development. The true speech starts when the child begins to develop meaningful association with expression and comprehension between the ages two to six years. By the age of four years the child begins to use grammar of his language. An average child's vocabulary increases up to 2,500 words by the age of six years. Hence early school hood education provides training in elementary language skills for all children to improve their comprehension and speech. The preschool educational institutions provide listening and language games which stimulate children's interest in learning.

Children develop their language skills with age and with the help of feedback given by adults i.e., reinforcing the correct responses. Kersner and Wright (1996, p.22) say that, "In the early stages of development children are quite sophisticated language users. They can make statements and describe things, and ask questions. The third years is often thought of as being the one when most linguistic progress occurs, although yet the child's speech is full of grammatical errors”.

Assessment of language ranges from understanding of simple words and progresses in logical sequence to the comprehension of the more complex aspects of grammar which are most important in early language 
development, questions, tenses and relative clauses. Brustall (1996, p.193) describes the basic linguistic skills to assess the second language proficiency at primary level as; "any investigation of second language learning at the primary level must entail the objective assessment of the four basic linguistic skills; listening compression, oral production, reading completion and written expression”. Private schools have always used English as a compulsory subject right from class one.

Shagufta (1997) has evaluated the course material for Class V. She says, "The position of English in our education system has a different picture. Initially, English was taught from sixth class to post-graduate level in all the government schools/colleges in provinces. It is very recently that English has been presented as a compulsory subject at primary level”.

In Pakistan pre-school education is mainly limited only to the schools in private sector. Very few schools in public sector have arrangements for pre-school education. However, arrangements for education from the age of three years up to five years are lacking, which may have lag behind the children from attaining good language skills. All over the world not much work and researches on pre-school education have been done. The present study was designed to identify the effect of pre-schooling on language comprehension of children at primary level.

Following specific objectives were formulated:-

1. To compare the performance of students on English language tests, who got pre-school education and the students who have not such experience in the early years of their life.

2. To find out/evaluate the effect of pre-school education on writing skills of students at primary level.

Hypothesis to be tested through the study was as under:

There is no significant effect of pre-school education on the language comprehension children at primary level.

The study was delimited to the: (i) Students (male and female) of class I to class V from the four English medium (model) schools situated in four sectors of Islamabad, (ii), the English language comprehension was tested only on the writing skills elements such as; organization of ideas, spelling, vocabulary, and parts of speech. The writing skills for class I and II and for entry classes were delimited only to the; recognition 
of alphabets, vocabulary, nouns, capitalization, and negative sentences, use of a, an, has, have and singular and plural.

\section{Literature Review}

The purpose of language is communication. Language skills describe different modes of communication. Speaking, listening, reading and writing describe communication in terms of sending and receiving spoken and written language. Reading and writing being the basic means of knowledge and culture are essential to a full life in a civilized community. In any language various symbols are used to represent objects, situations, and the everyday occurrence of life. These symbols may be spoken or written expressions.

English language is system of symbols governed by over 1000 grammatical rules, all of which are accepted and recognized throughout the world (Crystal, 1986). Young children understand the symbols of their own language gradually. They use language to express their own messages and to improve their communication. A study cited by Crystal (1986) shows that at seventeen months one child was able to use 1860 different types of words. These include nouns, naming people and different categories of objects, verbs, describing a variety of actions, descriptive words referring to location, and words such as 'more' and again.

\section{Language in Pre-school Years}

Leyden (1985, p.14) describes the pre-school years as:

The period of near complete dependency from the moment of birth to the time when the child becomes physically and emotionally able to explore beyond the nest-like environment of the home is the foundation stage for healthy future development. As physical strength and coordination increase the opportunities for exploration and then for learning increases. New experiences bring new awareness of both. Exploration and play is essential ingredient of physical and intellectual growth of children. In first two years the child explores his world but he sees it in the mirror of the adult's face that the child learns to interpret the new found knowledge.

Anonymous (1998) reported National Research Council on preschool education, which indicates that pre-school child needs to learn critical skills of understanding the alphabets, reading for meaning and 
reading fluently. Pinsent (1988) focuses on the language and literacy development of children from a variety of ethnic, cultural and language backgrounds from the earliest stages up to stage one. It starts from the assumption that the children's background is assets to them and to the nursery and infant schools which they attend.

Assessment of the language abilities of young children is often difficult for the teachers, even when their first language is English. For bilingual children, the problem is inevitably greater, and there is considerable danger that their abilities will not be recognized and they will be regarded as low achievers (Downing, 1979). Hill (1974) gives criteria of English language acquisition by defining aims at school leaving level; those are: i) Ability to understand simple English spoken by other people, ii) Ability to make oneself understood when speaking, iii) Ability to understand a none technical book written in ordinary English and iv) Ability to express ideas clearly and reasonably correctly in simple written English. Parren and Chari (1996, p.41) describe the use of second language as a medium of instruction in Asian countries. They view that whole progress of the pupil either in general education or in specialized studies depend on having an adequate command of language, other than his mother tongue. They say that:

If in Asia the status of English or French in primary education is unlike that in Africa, the problems of second language teaching are more complex. Countries such as India, Pakistan, Burma, Malaysia, Singapore, Thailand and the Philippines all have declared national language as a national language for educational use as well as a means to develop national unity. At the same time all of them wish to extend or maintain the teaching of a world language (English) as an essential auxiliary for technical and economic development. Although in the primary schools the major need is development towards improving the teaching of English.

English language is taught as a second language in our country. Learning of this second language takes place under formal instruction. Dlugosz, (2000) in his study says that early students of English, even those who have not yet learnt to read in their native tongue, will benefit from learning to read from the beginning of their contact with a foreign language. The study indicated that the early introduction to reading additionally speeds their progress in understanding and speaking the foreign language. The English-language development foundations developed by California Department of Education (Abbott, D. Lundin, J. \& Ong, F. (editors) (2008) for children entering preschool with a home language other than English. Through these foundations some English 
learners will begin preschool already having had some experience with English. For other English learners, preschool will offer them their first meaningful exposure to English. No matter how much background English learners have with English before they enter preschool, they will be on a path of acquiring a second language.

Oxford \& Spieker (2008) examined a comprehensive set of predictors of preschool language performance in a sample of 154 children born to adolescent mothers. Logistic regression revealed that having a poor language-learning home environment was associated with children's low language scores even after accounting for mothers' belowaverage verbal ability. Barnatt, \& Frede (2010, p.20) advocate on the basis of their research for universal access to high-quality preschool. They mean that the program for $3-4$ years develop their knowledge and skills across the content areas; language and literacy, math, science, social studies and the arts. They see preschool education as one part of a larger, multifaceted set of public investment in human development.

Writing skill involves the learning of using a syllable - symbol system or word-root/character system. According to Byrne (1979, p.27-28):

By using texts (letters and reports, for example - even dialogues in the early stages) as our basic practice formal, rather than some other unit such as the sentence or even the paragraph, we can make writing activities much more meaningful for the students and thereby increase their motivation to write well. The text provides a setting within which they can practice, for example, sentence completion, sentence combination, paragraph construction (etc.). In this way they can see not only why they are writing but also write in a manner appropriate to the communicative goal of the text.

Garton and Pratt (1998) are mainly concerned with the period when children are of ages 3 and 7 years. During this period children make attempts to write and discover the principles involved in writing. Learning to write involves mastering a diverse range of skills and understandings. Beginning English Language Instruction as prescribed in Curriculum Document, Primary Education, Classes K-V, National Bureau of Curriculum and Textbooks, Ministry of Education, Pakistan (1995) highlighted the specific learning objectives of writing for primary education classes $\mathrm{K}-\mathrm{V}$. Language comprehension in the present study was assessed on the basis of these objectives for classes I - V. 


\section{Methodology}

The research study was aimed at investigating the effect of a course (pre-school education) on difference in performance of children (preschoolers and non-preschoolers) on English language test was investigated through causal-comparative research method. The individuals of the groups (preschoolers and non-preschoolers) were different on only one variable that was preschool education.

\section{Participants}

All individuals studying at primary level, i.e., of classes one to five in Federal Government schools located in four sectors of Islamabad, comprised the population of this research. The individuals of both genders were different at only one variable that was the education they got in proper school setting for two to three years before they entered/promoted to class-I.

A randomly selected sample comprised of 240 children divided into two groups (preschooler and non-preschooler); i.e. 200 children; 40 children (20 preschoolers and 20 non-preschoolers) from each class from classes I to $\mathrm{V}$ and 40 for entry test.

As sample was needed to be taken from the four model schools, therefore, ten children (five preschoolers and five non preschoolers) from each class of classes one to five of each of the four schools were selected by simple random sampling method. The preschoolers were those children who started their first school at the age of 3 or 3 plus years. These students attended at least three classes before entering class I i.e., pre nursery, nursery/prep and then K.G. The non preschoolers were those children who started their first school at the age of five or six years before class-I except only informal coaching at home.

All the other independent variables such as socio-economic status, education of the parents, study habits of children, teachers qualifications, teacher's professional efforts, extra coaching at home as a contribution of parents towards the educational performance of children, all were considered as similar for both groups and hence have not been manipulated.

\section{Instruments}

The following instruments (tests) were constructed for the research study:-

1. Entry test in English language for class-I

2. English language test for class-I 
3. English language test for class-II

4. English language test for class-III

5. English language test for class-IV

6. English language test for class- $\mathrm{V}$

The entry test was constructed on the pattern of usual entry test of these schools containing items on recognition of alphabets, writing of alphabets, recognition of names of objects used in daily experiences of the children, concept of numbers, order, sequence and spellings of numbers and concept of two dimensional shapes. This test was administered to the children who had just enrolled in class-I. Whereas a test of English to other classes I - V were given to the children at the end of academic year when they had almost completed their syllabus.

Test items of the tests in English language for classes one to five were based on the English language instruction stated in curriculum document, primary education classes $\mathrm{K}$ to $\mathrm{V}$, integrated and subject based document of Government of Pakistan, 1995. The language composition in tests was limited to the following aspects:

1. Compositional aspects

a. vocabulary usage

b. grammar

c. sentences

d. paragraphs

2. Mechanical aspects

a. spellings

b. punctuation

c. capitalization

The above language components were defined and finalized after discussion with the teachers of English language. These components vary from class to class but attempts were made to equalize them at least for three upper primary classes, i.e. class III, IV and V. The questions in the tests were finalized on the following language aspects:

1. Test for Class- I

- Recognition of alphabets

- Spelling of common objects and words

- Use of 'a' and an'

- Construction of simple sentences

- capitalization

- Singular plural 
- $\quad$ Spellings of numbers upto 20

- Conversion into negative sentences

- writing of familiar vocabulary (names of colours and fruits)

2. Test for Class - II

- Use of pronouns

- Construction of simple sentences

- gender, singular and plural

- $\quad$ spellings of words

- $\quad$ use of 'has' and 'have', to, for

- proper and common nouns

- use of articles

- forms of verbs

- names of days of the week, shapes

- time concept

- punctuation

3. Test for Class-III

- simple questions and answers

- $\quad$ forms of verbs

- proper and common nouns

- simple action words

- common adjectives

- preposition, courtesy expression

- negative forms of present and past tense

- pronouns

- construction of sentences

- gender, singular plural, opposites and directions

- pronouns and belongings

- use of no, any

4. Test for Class - IV

- degrees of adjectives

- gender, singular plural, opposite

- construction of sentences of new vocabulary

- use of appropriate verbs, noun, proposition

- correct incorrect

- $\quad$ spellings of numbers up to 100

- paragraph writing (simple composition) 


\section{Test for Class - V}

- Use of appropriate word to complete the sentence from the given list

- use of how many, how much, where, whose, etc.

- forms of verbs

- $\quad$ construction of sentences (use of new vocabulary)

- $\quad$ spellings of numbers up to 500

- names of months of a year

- words of similar meaning, similar sound

- Comprehension (write answer of the given questions after reading the given text).

- Gender, singular plural and opposites

- Writing letters

- Writing simple sentences in the present, past and future tense

- Paragraph writing

The test items were spread over all types, i.e., multiple choices; fill in the blanks, matching, correct and incorrect, short answer and composition. The tests were formulated on the language skills in writing mentioned in Curriculum Document of Ministry of Education, Government of Pakistan, 1995. All the tests were pre tested over a group of 25 children, five from each class. As a result of pilot testing the item analysis was carried out and the items having 100\% and 90\% level were removed. The retained items have a range of variability between 35 and 86. The alpha reliability of the instruments/tests for classes I to $\mathrm{V}$ and for the entry test was within a range of .80- .88.

\section{Data Analysis}

The mean scores of both groups 20 preschoolers and 20 non preschoolers for each class were calculated and test for independent sample was applied in order to determine whether two means were significantly different at 0.05 level of significance or not. In case of significant difference the null hypothesis was not accepted.

\section{Results}

The performance of children on entry test and those of classed I - V on English language tests was evaluated by awarding marks on each test. Maximum numbers of tests for each class were 100 . Both groups were 
compared by calculating the means and their differences through $\mathrm{t}$ values for independent variable. The tabular representation of the data analysis is given below.

Table 1

Performance of Children on Entry Test

\begin{tabular}{llllll}
\hline Test & Variable & $\mathrm{M}$ & SD & $\mathrm{t}$ & $p$ \\
\hline Entry & Preschool (n1=20) & 88.4 & 5.400 & \multirow{2}{*}{15.077} & \multirow{2}{*}{0.000} \\
test & Non preschool (n1=20) & 34 & 15.294 & & \\
\hline
\end{tabular}

The table 1 shows the comparison of performance of performance of the children of both groups, i.e. preschoolers and non-preschoolers on entry test. Calculation of the means of both groups is 88.4 and 34 respectively while calculated t value is 15.077 and $p$ is .000 , therefore null hypothesis about the performance of preschoolers and non preschoolers on entry test is rejected.

Table 2

Performance of Children on English Test

\begin{tabular}{clllcc}
\hline Test & \multicolumn{1}{c}{ Variable (n) } & \multicolumn{1}{c}{ M } & \multicolumn{1}{c}{ SD } & \multicolumn{1}{c}{$\mathrm{t}$} & \multicolumn{1}{c}{$p$} \\
\hline Class I & Preschool (20) & 85.10 & 6.172 & \multirow{2}{*}{19.26} & .000 \\
& Non preschool (20) & 31.15 & 11.040 & & \\
Class II & Preschool (20) & 81 & 6.349 & 10.525 & .000 \\
& Non preschool (20) & 35.7 & 15.068 & & \\
Class III & Preschool (20) & 76.6 & 6.931 & \multirow{2}{*}{17.44} & .000 \\
& Non preschool (20) & 33.6 & 8.574 & & \\
Class IV & Preschool (20) & 80.2 & 8.408 & \multirow{2}{*}{15.548} & .000 \\
& Non preschool (20) & 35.25 & 9.824 & & \\
Class V & Preschool (20) & 75.85 & 7.596 & \multirow{2}{*}{15.705} & .000 \\
& Non preschool (20) & 38.15 & 7.583 & & \\
\hline
\end{tabular}

The table 2 indicates the comparison of performance of the children of both groups; preschoolers and non-preschoolers on English test for class 1 - V. Calculation of the means of both groups is 85.10 and 31.15 respectively while calculated t value is 19.26 and $p=.000$ which shows significant difference at .01 level, therefore null hypothesis about the performance of preschoolers and non-preschoolers on English language test for class-1 is rejected. The comparison of performance of the children of both groups on English test for class-II shows that the means of both groups is 81 and 35.7 respectively while calculated t value is 
10.525 and $\mathrm{p}=.000$ which shows significant difference at .01 level, therefore null hypothesis about the performance of preschoolers and nonpreschoolers on English language test for class-2 is rejected. Similarly the comparison of performance of the children of both groups on English language test for class-III shows that the means of both groups is 76.6 and 33.6 respectively while calculated $t$ value is 17.44 and $p=.000$ which shows significant difference at .01 level, therefore null hypothesis about the performance of preschoolers and non-preschoolers on English language test for class-3 is rejected. The comparison of performances of the children of both groups on English language test for class-IV shows that the means of both groups is 80.2 and 35.25 respectively while the calculated $\mathrm{t}$ value is 15.548 and $\mathrm{p}=.000$ which shows significant difference at .01 level, therefore null hypothesis about the performance of preschoolers and non-preschoolers on English language test for class4 is rejected. Similarly the means of both groups is 75.85 and 38.15 respectively while calculated t value is 15.705 and $\mathrm{p}=.000$ which shows significant difference at .01 level, therefore null hypothesis about the performance of preschoolers and non-preschoolers on English language test for class-5 is rejected.

\section{Conclusions}

The following conclusions were drawn:

1. Children from the age of three or three plus years through proper school programs have clear concepts of language. They understand the English language more clearly than the children who had not gone through the proper school programs in the early years of their lives.

2. Preschool education contributes in the comprehension of English language of children, i.e. increase the vocabulary and spellings. It enables the children to organize their ideas and to choose appropriate words to construct the sentences and to write on a given topic.

3. Pre-school education significantly affects the performance of the students in their studies at primary level.

4. There is a significant effect of pre-school education on writing skills of students at primary level.

5. It was concluded that children who attended pre-school programs:-

a. Organize their ideas in a logical sequence.

b. Know good and correct usage of grammar.

c. Construct good sentences on the given words 
d. Know the proper use of verbs, adverbs, articles, pronouns, prepositions, adjectives etc.

e. Have a great deal of vocabulary

f. Know punctuation of English language

g. Perform well on comprehension questions

h. On entry in class I, they were familiar with the vocabulary of common use, know and can write the names of things in their environment, fruits, colors and shapes. They also have very clear concept of English alphabets. They knew the correct formation of letters. They are well aware of capitalization.

i. Make minimum mistakes in spellings.

6. Pre-school education significantly contributed toward the performance of children on entry test for class-I.

7. The preschooler is usually high achiever.

\section{Recommendations}

Keeping in view the results of the study the following recommendations were made:

1. The children should be sent to the schools from the age of three or three plus years.

2. Parents are recommended to provoke the learning of children by providing them preschool education.

3. The curriculum developer should look seriously into the pre- school curricula as the developed countries in the world had done.

4. All the schools must have preschool classes to accommodate the increasing need of the society.

5. There should be great emphasis on the pre-school education or (prep classes) in the National Education Policy.

6. In the present era of advance technology children have approach to the knowledge delivering instruments, which are continuously contributing towards, enlighten their curiosity and thinking, demand of further knowledge and improving their learning. Therefore the policy makers are recommended to create a room for the very young children of our country to fulfill their thirst of knowledge.

7. Teachers are recommended to produce healthy minds through teaching at preschool level.

8. Researchers are recommended to critically evaluate the present curricula and preschool programs for the betterment. 


\section{References}

Abbott, D. Lundin, J. \& Ong, F. (editors) (2008). California Preschool Learning Foundations-Volume 1 developed by the Child Development Division, California: California Department of Education through a contract with WestEd.

Anonymous (1958). "Report of National Research Council on Pre-school Education, on Preparing Children for Reading” in Futurist (FUS).

Barnatt, W.S. \& Frede, E. (2010).Benefits of Preschool. American Educators, Spring 2010:21-40.

Brustall, C. "The Main Stages in the Development of Language Tests" in Stern, H.H. (1996) Language and the Young School Child London: Oxford University Press.

Byrne, D. (1979). Teaching Writing Skills Harlow, Essex: Longman Group UK Ltd.

Crystal, D. (1986). Prosodic development. In Fletcher, P. \& Garman, M., editors, Language acquisition, $2^{\text {nd }}$ ed., Cambridge: Cambridge University Press.

Dlugosz, D.W. "Rethinking the role of Teaching a Foreign Language to Young Learners” ELT Journal Vol.54/3, July 2000, pp.284-290.

Downing, J. (1979). Reading and Reasoning. New York: SpringerVerlag.

Garton, A. and Pratt, C. (1993). Learning to be Literate: The Development of Written and Spoken Language $3^{\text {rd }}$, Oxford: Blackwall Publishers.

Government of Pakistan (1995) Curriculum Document Primary Education K-V Integrated and Subject Based Islamabad: National Bureau of Curriculum and Text Books Ministry of Education.

Hill, L.A. (1974) Selected Articles on the Teaching of English as a Foreign Language $3^{\text {rd }}$, London: Oxford University Press. 
Kersner, M. and Wright, J.A. (1996). How to Manage Communication Problems in Young Children: $2^{\text {nd }}$ London: David Fulton Publisher Ltd.

Krashen, S.D. and Tarrell, T.D. (1983). The Natural Approach: Lang Acq. in the classroom Oxford: Pergamon Press.

Langan, J. (1981). English Skills 2 ${ }^{\text {nd }}$, New York: McGraw Hill Book Company.

Leyden, S. (1985). Helping the Child of Exceptional Ability London: Croom Helium Ltd.

Lucasand, T. and Handerson, A. (1985). Pre-School Playgroups: A Handbook $3^{\text {rd }}$, London: George Alleyn and Unwin, Publishers Ltd.

Miller, D.J., Munno, S.M. and Code, C. (1986). Language Assessment for Remediation. London: Croom Helm

National Education Goals Panel (1991). The Goal 1 Technical Planning Subgroup Report on School Readiness. Washington DC: NEGP, 1991.

Oxford, M. \& Spieker, S. (2008). Preschool language development among children of adolescent mothers. Journal of Applied and Developmental Psychology, 27 (2): 165-182.

Page, G.T. and Thomas, J.B. (1979). International Dictionary of Education London: The English Language Society and Kagan Press.

Perren, G.E. and Chari, A. "Second Language Teaching to Younger Children in Africa and Asia” London: Oxford University Press.

Powers, S. et al. (1985). “Assessing Language Proficiency from a Sociolinguistic Perspective”. TESOL: teachers of English to Speakers of other Languages, Vol.20, Issue 3, September 1986, pp.562-563.

Pinsent, P. (edi) (1988). Language Culture and Young Children London: David Fulton Publishers Ltd. 
Schafer, G. and Plunkett, K. (1998). Rapid word learning by 15-montholds under tightly-controlled conditions. Child Development, Vol:69, (2), Apr.1998, p.309-320. ISSN 0009-3920 doi: DOI:10.1111/j.14678624.1998.tb06190.x.

Shagufta F. (1997). "Development of EFL Teaching Material for Gradefive, Development of English Language and Applied Linguistics”, An unpublished Thesis of M.A. TEFL, Allama Iqbal Open University, Islamabad, December, 1997.

Stern, H.H (Ed.) (1996), Language and The Young School Child, London: Oxford University Press.

The New Encyclopedia Britannica Macropaedia Vol. 14. $15^{\text {th }}$ ed. Encyclopedia Britannica Macropaedia, Inc. USA .

Received on: February 22, 2016

Revised on: May 11, 2016

Accepted on: June 05, 2016 